\title{
BE YOUR OWN BOSS, ANYONE? EARNINGS, EMPLOYMENT CHANCES AND JOB CHOICE OF FRESH UNIVERSITY GRADUATES
}

\author{
Jan-Jan Soon* \\ Universiti Utara Malaysia \\ Hock-Eam Lim \\ Universiti Utara Malaysia \\ Siti Aznor Ahmad \\ Universiti Utara Malaysia
}

\begin{abstract}
Whether or not one can get employed, how much one can earn, and what types of job one gets are typically the main concerns of newly minted university graduates. In this study, we have collected data from fresh graduates of two public universities in Malaysia, i.e. on actual job choices that fresh graduates have made, their monthly earnings, and whether or not they are employed. With these data, our study contributes to the empirical literature and focuses on the issue of whether or not entrepreneurship education is significant in influencing earnings, employment probabilities, and types of job. The main conclusions from our findings are (i) graduate entrepreneurs' monthly earnings are higher than graduates employed in qualification-mismatched jobs, but lower than those with qualification-matching jobs, (ii) graduates with entrepreneurship degrees earn less than those with non-entrepreneurship degrees, (iii) having an entrepreneurship degree has no significant influence on employment chances, and (iv) an entrepreneurship degree also is also insignificantly associated with any of the probabilities of landing a job that is either commensurate or incommensurate with one's degree, or the probabilities of being unemployed.
\end{abstract}

Keywords: Employment Probability; Earning; Job Choice; Graduate Entrepreneur.

\section{INTRODUCTION}

In line with the aspirations of the $10^{\text {th }}$ Malaysian Plan $(2011$ - 2015) to create an entrepreneurial culture, Malaysian universities have been tailoring their curricula to produce more graduate entrepreneurs. In fact, in as early as during the $9^{\text {th }}$ Malaysian Plan (2006 - 2010), the government has even allocated RM25million to set up the Graduate

\footnotetext{
- Corresponding author. Economics Building, School of Economics, Finance \& Banking, Universiti Utara Malaysia, 06010 Sintok, Kedah, Malaysia. Tel: +6049286834. Email: soon@uum.edu.my
} 
Entrepreneur Fund to encourage university graduates to be entrepreneurs. Although entrepreneurship education at the university level is being implemented as a core subject in many Malaysian universities compulsory for graduation, and as a whole degree programme itself in some universities, graduates do not seem keen to become entrepreneurs. The Global Entrepreneurship Monitor (2010) also reports low rates of early-stage entrepreneurial activity (budding and new small-and-medium businesses) for Malaysia, i.e. the third lowest rate among 23 countries, in which Malaysia's rate is $4.96 \%$ compared to the highest rate, Colombia's $20.61 \%$.

Entrepreneurship education at the university level is perceived as ineffective in creating new generations of graduate entrepreneurs in Malaysia (Cheng et al 2009; Sandhu et al 2011). In fact, the 2010 Malaysian Graduate Tracer Study reports only about a paltry $1.4 \%$ out of the 48,709 public university graduates are self-employed or entrepreneurs, as opposed to $61.3 \%$ being employed in full-time jobs (MOHE 2011, p. 204). Studies on the effectiveness of Malaysian entrepreneurship education in producing graduate entrepreneurs revolve around intentions or inclinations (Ooi et al 2011; Mohamed et al 2012; Mohamad et al 2014), perceptions (Cheng et al 2009; Sandhu et al 2011), and readiness (Othman et al 2012).

These studies however, are unable to provide estimates of earnings, employment probabilities, and actual job choices of fresh graduates. In this current study, we address this empirical issue and the issue of the effectiveness of entrepreneurship education in Malaysian public universities. The main objective of our study is to see to what extent fresh university graduates fare in terms of earnings, employment chances, and the choice of jobs, especially for those with Entrepreneurship degrees.

\section{ESTIMATION STRATEGY AND MODEL SPECIFICATION}

\subsection{Data}

Our target population are local graduates from public universities in Malaysia. The data used for this study are collected through self-administered questionnaire distributed to respondents from two Malaysian public universities in November 2014, where respondents are approached during the graduation robe collection week, just prior to their graduation ceremony. We use a census approach, where all graduates are approached when they register at the robe collection counter. However, since response to the survey is on a voluntary basis, not all of the graduates agree to participate. The original data set has a total of 1,723 respondents/observations. From a total of 6000 -odd number of graduates, this number of respondents makes up a response rate of about $29 \%$. Upon data checking and cleaning, 16 observations are deleted because they gave impossible answers to the question on whether or not they are employed (at the time of the survey), i.e. both employed and unemployed options are selected. We also deleted one observation due to its unrealistically large reported monthly salary. The final working data set therefore consists of 1,706 observations. 


\subsection{Estimation models}

Using three estimation models, we look at the employment chances, earnings, and job choice of newly minted graduates. First, we use an OLS regression model to examine the marginal effects of the regressors on earnings. We define earnings as either employees' salaries or entrepreneurs' income.

$y=X \beta+\varepsilon$

where $y$ and $\varepsilon$ are $n \times 1$ vectors, while $\beta$ is a $k \times 1$ vector. $X$ is an $n \times k$ matrix with $k$ explanatory variables for $n$ observations. The constant term is subsumed in one of the columns in $X$ matrix. We use the natural logarithm of earnings as the $y$, while $X$ consists of demographic, socioeconomic, academic, and programme-related variables. $\varepsilon$ is the vector of error terms.

In a second estimation model, we use a binary probit model to examine the probabilities of being employed. We define being employed as having a job, regardless of whether as employees or self-employed (i.e. as entrepreneurs). The model is as follows.

$\operatorname{Prob}(y=1 \mid X)=\Phi(X \beta)$

where $y=1$ if a graduate is being employed at the time of the survey, and $\Phi(\cdot)$ is the standard normal distribution function.

Following the binary probit model, we use a multinomial logit (MNL) model with a 4category outcome variable to examine the probabilities of (i) having jobs that are commensurate with the graduates' university qualifications, (ii) having jobs that are incommensurate with qualifications, (iii) being entrepreneurs, and (iv) being unemployed. Our 4-outcome $(J=4)$ MNL model is as follows. Note that the $i$ subscript for $y$ and $X$ is dropped to avoid notational clutter.

$\operatorname{Prob}(y=j \mid X)=\frac{e^{X \beta_{j}}}{\sum_{j=1}^{J} e^{X \beta_{j}}}, j=1, \ldots, 4$

\section{RESULTS AND DISCUSSION}

There are two main parts to this section. First, we discuss some of the summary statistics of the data set. We then discuss the main findings from the three estimation models.

\subsection{Summary statistics}

Table 1 reports summary statistics of the two sets of regressors by employment status. Summary statistics are in proportions, except for age, household size, CGPA, and earnings 
(in RM'000/month). With perhaps the exception of the ethnic group variable, there is not much difference in magnitude for the demographic and socioeconomic variables by employment status. From our pool of respondents, $80 \%$ of those who are unemployed (at time of survey) are of the Malay ethnic group. For those who are working, slightly more than $60 \%$ are of the Malay ethnic group.

Table 1: Summary statistics

\begin{tabular}{lcc}
\hline \hline \multicolumn{1}{c}{ Variables } & Employed & Unemployed \\
\hline $\begin{array}{l}\text { Demographic \& socioeconomic } \\
\text { Age }\end{array}$ & $25.4(1.89)$ & \\
Female & $0.67(0.47)$ & $25.3(1.87)$ \\
Malay & $0.62(0.49)$ & $0.65(0.48)$ \\
Household size & $5.8(2.16)$ & $0.80(0.40)$ \\
Father's income $\leq$ RM3,000 & $0.64(0.48)$ & $6.2(2.57)$ \\
Academic \& programme-related & & $0.65(0.48)$ \\
Entrepreneurship & $0.07(0.26)$ & \\
${ }^{1}$ Business & $0.13(0.33)$ & $0.08(0.27)$ \\
Accounting & $0.11(0.31)$ & $0.09(0.29)$ \\
${ }^{2}$ Economics & $0.10(0.29)$ & $0.07(0.25)$ \\
${ }^{3}$ MUET Band 1-2 & $0.46(0.50)$ & $0.07(0.25)$ \\
MUET Band 3 & $0.42(0.49)$ & $0.61(0.49)$ \\
MUET Band 4-6 & $0.10(0.30)$ & $0.32(0.47)$ \\
${ }^{4}$ CGPA & $3.29(0.29)$ & $0.06(0.23)$ \\
Job-related & & $3.24(0.28)$ \\
Earnings (Overall) & $1,754(779)$ & - \\
Commensurate $(n=480)$ & $2,103(630)$ & - \\
Incommensurate $(n=275)$ & $1,270(541)$ & - \\
$\quad$ Entrepreneur $(n=30)$ & $1,750(1570)$ & 845 \\
Number of observations, $N$ & 861 & - \\
\hline \hline
\end{tabular}

Notes: Figures in parentheses are standard deviations. Total number of observations is $861+845=1,706 .{ }^{1}$ Business administration/management; ${ }^{2}$ Economics, Finance \& Banking; ${ }^{3}$ Band 1: Extremely limited user, Band 2: Limited user, Band 3: Modest user, Band 4: Competent user, Band 5: Good user, Band 6: Very good use; ${ }^{4}$ Cumulative Grade Point Average.

The largest numbers of our respondents are graduates in business administration $(n=186)$, followed by graduates in accounting $(n=154)$, graduates in economics/finance/banking $(n=150)$, and graduates in entrepreneurship $(n=133)$. These are the four major degree programmes of our respondents, from a total of 77 different programmes obtained in our sample. Only $7 \%$ of those who are working have an entrepreneurship university qualification. Comparatively, $13 \%$ of those who are working have a university degree in business administration. Similarly $11 \%$ are accounting graduates and $10 \%$ are graduates in economics, finance, or banking. Among those who are unemployed, about $60 \%$ of them have the lowest Malaysian University English Test (MUET) score band, compared to about $30 \%$ and $6 \%$ of those with middle-range and the highest score bands. As for academic performance in university, measured by CGPA, those who are employed have a slightly higher average CGPA (3.29) than that of the unemployed (3.24). 
The bottom panel of Table 1 lists the overall average earnings, and average earnings by types of job. Graduates with jobs that are commensurate with qualifications have the highest earnings, while those with jobs that are incommensurate with qualifications earn the least. This is somewhat expected. For graduate entrepreneurs or those who are selfemployed, their average earnings are higher than graduates in mismatched jobs but lower than graduates with qualification-matching jobs. The earning distribution and spread by the three job types are shown in Figure 1.

Figure 1: Probability density functions

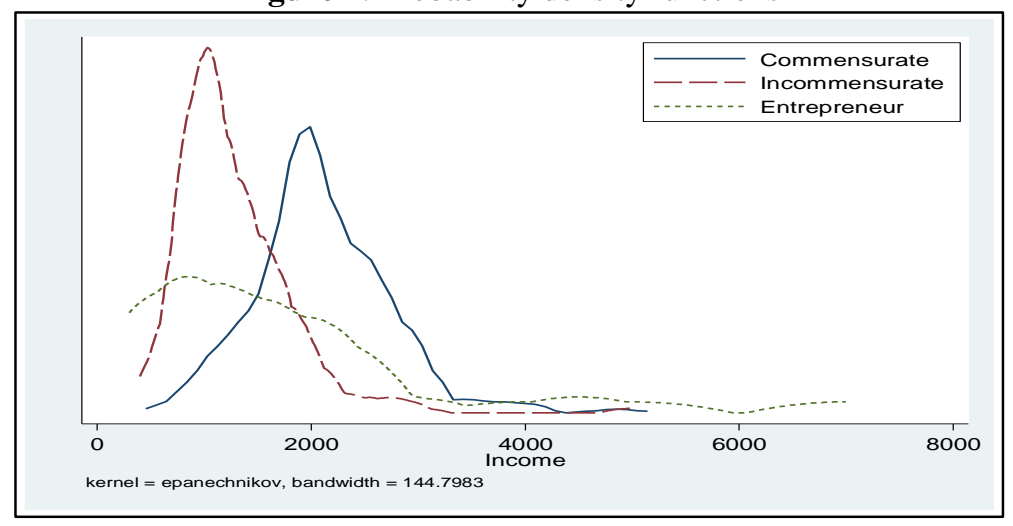

\subsection{Main estimation results}

Table 2 shows the estimation results from the OLS regression model on earnings and marginal effects from the probit model on employment chances of fresh graduates. We use two sets of main regressors, demographic/socioeconomic-related and academic/programme-related regressors for the two outcome/dependent variables. Using different specifications serves as robustness check. Comparing between specification (1) and (2) for earnings, and between specification (3) and (4) for employment chances, the results are fairly robust, especially in terms of coefficient signs.

In specification (2) and (4), we use a nonlinear specifications with squared and interaction terms. In these two specifications, we also compute the cluster-robust standard errors, clustered at university programme level. We have approximately 1,700 respondents with qualifications in 77 different university programmes. It is possible that the outcome (earnings or employment chances) within each university programme may be correlated, i.e. the error terms are correlated within each programme (but uncorrelated across programmes). By using cluster-robust standard errors, we allow for plausible heterogeneity across different programmes.

\subsection{On earnings}

In Table 2, specification (1) and (2) use OLS regression on a semi-log model, i.e. taking the natural logarithm of monthly earnings as its dependent variable. Older graduates earn 
more, while those from the Malay ethnic group and from large families tend to have lower earnings. From specification (1), at a p-value of 0.078 , it appears that having an entrepreneurship university degree decreases earnings by about $10 \%$. This association however, becomes insignificant in specification (2). Having a business administration university degree is associated with about $7 \%$ increase in earnings, while having a degree in accounting or economics, finance and banking does not seem to be significantly associated with earning powers. Academic performance (CGPA), on the other hand, is found significantly associated with earnings, although its magnitude is rather inconsequential. For example, from specification (2), a 0.1 increase in CGPA only brings about a $2.4 \%$ increase in earnings.

Table 2: Earnings and employment chances

\begin{tabular}{|c|c|c|c|c|}
\hline & \multicolumn{2}{|c|}{$\mathrm{Y}=\ln ($ Earnings $)$} & \multicolumn{2}{|c|}{ Y $=\operatorname{Pr}($ Employed $)$} \\
\hline & (1) & (2) & (3) & (4) \\
\hline \multicolumn{5}{|c|}{ Demographic \& socioeconomic } \\
\hline \multirow[t]{2}{*}{ Age } & 0.234 & $0.034 * *$ & $0.143 * * *$ & $0.147 * *$ \\
\hline & $(0.170)$ & $(0.014)$ & $(0.051)$ & $(0.068)$ \\
\hline \multirow[t]{2}{*}{ Female } & $-0.093 * * *$ & -0.076 & 0.042 & 0.075 \\
\hline & $(0.036)$ & $(0.047)$ & $(0.027)$ & $(0.047)$ \\
\hline \multirow[t]{2}{*}{ Malay } & $-0.325 * * *$ & $-0.271 * * *$ & $-0.186 * * *$ & $-0.169 * * *$ \\
\hline & $(0.038)$ & $(0.072)$ & $(0.030)$ & $(0.059)$ \\
\hline \multirow[t]{2}{*}{ Household size } & $-0.066 * *$ & $-0.021 * *$ & $0.039 * *$ & $0.045^{* *}$ \\
\hline & $(0.028)$ & $(0.010)$ & $(0.021)$ & $(0.021)$ \\
\hline \multirow[t]{2}{*}{ Income $\leq \mathrm{RM} 3,000$} & -0.002 & -0.013 & 0.004 & 0.092 \\
\hline & $(0.036)$ & $(0.043)$ & $(0.027)$ & $(0.078)$ \\
\hline \multicolumn{5}{|c|}{ Academic \& programme-related } \\
\hline \multirow[t]{2}{*}{ Entrepreneur } & $-0.107 *$ & -0.101 & 0.050 & 0.047 \\
\hline & $(0.060)$ & $(0.111)$ & $(0.049)$ & $(0.044)$ \\
\hline \multirow[t]{2}{*}{ Business } & 0.074 & $0.072 * *$ & $0.100 * *$ & $0.101 * * *$ \\
\hline & $(0.055)$ & $(0.033)$ & $(0.041)$ & $(0.027)$ \\
\hline \multirow[t]{2}{*}{ Accounting } & 0.001 & 0.001 & $0.151 * * *$ & $0.149 * * *$ \\
\hline & $(0.056)$ & $(0.038)$ & $(0.044)$ & $(0.032)$ \\
\hline \multirow[t]{2}{*}{ Economics } & -0.046 & -0.045 & $0.126 * * *$ & $0.124 * *$ \\
\hline & $(0.059)$ & $(0.046)$ & $(0.044)$ & $(0.053)$ \\
\hline \multirow[t]{2}{*}{ CGPA } & $0.229 * * *$ & $0.236 * * *$ & 0.031 & 0.034 \\
\hline & $(0.066)$ & $(0.068)$ & $(0.050)$ & $(0.071)$ \\
\hline \multirow[t]{2}{*}{ MUET 1-2 } & $-0.099 *$ & -0.081 & $-0.123 * *$ & -0.105 \\
\hline & $(0.059)$ & $(0.096)$ & $(0.049)$ & $(0.073)$ \\
\hline \multirow[t]{2}{*}{ MUET 3} & -0.021 & -0.018 & -0.019 & -0.001 \\
\hline & $(0.057)$ & $(0.071)$ & $(0.049)$ & $(0.060)$ \\
\hline Nonlinear & - & $\checkmark$ & - & $\checkmark$ \\
\hline Clustered s.e. & - & $\checkmark$ & - & $\checkmark$ \\
\hline$N$ & 570 & 563 & 1563 & 1541 \\
\hline
\end{tabular}

Notes: Significant at the ***1\%,**5\%, and *10\% level. Standard errors are shown in parentheses. Nonlinear specifications include squared and interaction terms. Clustered robust standard errors are computed for specification (2) and (4), clustered at the university programme level. 
CGPA is potentially endogenous to earnings, i.e. the error term in equation (1) may contain an omitted variable that is uncorrelated with all the variables in $X$ except $x_{k}$ (i.e. CGPA). In our context, the unobserved omitted variable can be, for instance, being workdriven or passionate about one's job - which is plausibly correlated with CGPA. If CGPA is indeed endogenous, i.e. $\operatorname{Cov}\left(x_{k}, \varepsilon\right) \neq 0$, then OLS estimation of equation (1) produces biased and inconsistent estimates of $\beta$. Testing for endogeneity at the 5\% significance level, both Wu-Hausman and Durbin-Wu-Hausman tests reject the null hypothesis that the CGPA is exogenous.

We therefore instrument the endogenous CGPA with $z$, i.e. whether or not the university programme has been the students' first choice programme. We use this instrument to generate only exogenous variations in CGPA. This 'first choice programme' instrument can be regarded as correlated with CGPA, but at the same time, it is not directly associated with earnings. From the first-stage effects of the instrument on CGPA (unreported here), we obtain a nonzero instrument coefficient estimate with a p-value of 0.003 , indicating $\operatorname{Cov}\left(x_{k}, z\right) \neq 0$. Our 2SLS estimation results (unreported here) shows that for every 0.1 increase in CGPA, earnings increase by about $13.9 \%$, with a p-value of 0.034 .

\subsection{On employment chances}

In specification (3) and (4) of Table 2, we use a binary probit model to estimate the marginal effects of the regressors on employment chances or the probability of having a job. It seems that maturity in terms of age can increase the chances of getting a job; a graduate who is a year older increases his chances of getting a job by about 14 to 15 percentage points. Graduates from the Malay ethnic group, compared to their non-Malay counterparts, see a decrease of about 16 to 19 percentage points in their chances of getting a job. It also appears that family setting plays a role in the graduates' employment chances, in which those from larger families are likelier to have a job, compared to those from smaller families.

Of the four major university programmes, graduates in accounting have the highest probability of having a job, ranging between 14 to 15 percentage points, i.e. from specification (3) and (4). This finding is consistent with that of Lim's (2007). His findings show that accounting graduates have the best employment performance indicators, compared to graduates with other non-accounting degrees.

There is also a significant and positive association between being graduates with degrees in business or economics/finance/banking and the probabilities of having a job. Having an entrepreneur degree however, does not suggest any significant association with such probabilities, although the association is positive. Specification (3) shows that graduates with the lowest MUET score bands experience lower chances of getting a job, by about 12 percentage points, compared to graduates with the highest MUET score bands. Our findings here are consistent with those by Lim (2010) and Lim and Bakar (2004), where their findings show graduates with better English proficiency tends to have better employment outcome. As opposed to its strong association with earnings, a one-point 
increase in CGPA here shows no significant relationship with the probability of having a job. A test on the endogeneity of CGPA (with a p-value of 0.594 ) also reveals no empirical evidence that CGPA is being endogenous to the probability of having a job.

\subsection{On job choice}

Table 3 shows the marginal effects of the regressors from MNL estimations on the fourcategory outcome variable - choice of job. Most of the regressors only show discernible significance on two of the outcomes, i.e. the 'Commensurate' and 'Unemployed' outcomes, but not so much on the remaining two outcomes ('Incommensurate' and 'Entrepreneur').

Table 3: Choice of job

\begin{tabular}{|c|c|c|c|c|}
\hline & $\begin{array}{c}\text { Commensurate } \\
Y=1\end{array}$ & $\begin{array}{c}\text { Incommensurate } \\
Y=2\end{array}$ & $\begin{array}{c}\text { Entrepreneur } \\
Y=3\end{array}$ & $\begin{array}{c}\text { Unemployed } \\
Y=4\end{array}$ \\
\hline \multicolumn{5}{|c|}{ Demographic \& socioeconomic } \\
\hline \multirow[t]{2}{*}{ Age } & $0.079 *$ & 0.039 & 0.014 & $-0.133 * *$ \\
\hline & $(0.048)$ & $(0.035)$ & $(0.051)$ & $(0.063)$ \\
\hline \multirow[t]{2}{*}{ Female } & 0.010 & 0.068 & -0.016 & -0.062 \\
\hline & $(0.039)$ & $(0.051)$ & $(0.019)$ & $(0.048)$ \\
\hline \multirow[t]{2}{*}{ Malay } & $-0.236 * * *$ & $0.079 *$ & 0.021 & $0.136 * *$ \\
\hline & $(0.042)$ & $(0.048)$ & $(0.014)$ & $(0.061)$ \\
\hline \multirow[t]{2}{*}{ Household size } & $0.037 * *$ & -0.001 & 0.002 & $-0.038^{*}$ \\
\hline & $(0.018)$ & $(0.011)$ & $(0.006)$ & $(0.021)$ \\
\hline \multirow[t]{2}{*}{ Income $\leq \mathrm{RM} 3,000$} & $0.103^{*}$ & 0.027 & -0.034 & -0.095 \\
\hline & $(0.057)$ & $(0.073)$ & $(0.027)$ & $(0.075)$ \\
\hline \multicolumn{5}{|c|}{ Academic \& programme-related } \\
\hline \multirow[t]{2}{*}{ Entrepreneur } & 0.002 & 0.031 & 0.005 & -0.040 \\
\hline & $(0.032)$ & $(0.026)$ & $(0.012)$ & $(0.039)$ \\
\hline \multirow[t]{2}{*}{ Business } & 0.034 & $0.051 * * *$ & $-0.017 * *$ & $-0.068^{* *}$ \\
\hline & $(0.021)$ & $(0.013)$ & $(0.007)$ & $(0.026)$ \\
\hline \multirow[t]{2}{*}{ Accounting } & $0.112 * * *$ & 0.020 & -0.004 & $-0.136^{* * *}$ \\
\hline & $(0.025)$ & $(0.016)$ & $(0.005)$ & $(0.032)$ \\
\hline \multirow[t]{2}{*}{ Economics } & 0.046 & $0.043 * * *$ & 0.014 & $-0.104 * *$ \\
\hline & $(0.041)$ & $(0.015)$ & $(0.009)$ & $(0.048)$ \\
\hline \multirow[t]{2}{*}{ CGPA } & $0.112 * *$ & -0.050 & -0.019 & -0.042 \\
\hline & $(0.055)$ & $(0.030)$ & $(0.012)$ & $(0.062)$ \\
\hline \multirow[t]{2}{*}{ MUET 1-2 } & $-0.102 *$ & 0.012 & -0.007 & 0.098 \\
\hline & $(0.055)$ & $(0.038)$ & $(0.012)$ & $(0.064)$ \\
\hline \multirow[t]{2}{*}{ MUET 3} & -0.031 & 0.029 & 0.004 & -0.002 \\
\hline & $(0.041)$ & $(0.031)$ & $(0.012)$ & $(0.050)$ \\
\hline
\end{tabular}

Notes: Significant at the $* * * 1 \%, * * 5 \%$, and $* 10 \%$ level. Standard errors are shown in parentheses. Nonlinear specification - squared and interaction terms - is used in the multinomial logit model. Clustered robust standard errors are computed, clustered at the university programme level. For the MNL estimations here, the total number of observations used is 1,540 .

Older graduates are likelier to be working in jobs that are commensurate with their qualifications, and also less likely to be unemployed. Graduates from the Malay ethnic 
group however, see approximately a 24 percentage point drop in their likelihood of working in jobs that are commensurate with their qualifications, and at the same time are likelier to be unemployed. They are also likely to be working in jobs that do not match their qualifications. Graduates coming from big families and also those who are from relatively poorer households have higher chances of working in jobs that match their qualifications.

The marginal effects of the type of university programmes on job choice are somewhat mixed. Graduates with accounting degrees stand to increase their chances of getting jobs that matched their degrees, by about 11 percentage points, and their chances of being unemployed decrease by almost 14 percentage points. The magnitude of these two marginal effects on $\operatorname{Prob}(Y=1)$ and on $\operatorname{Prob}(Y=4)$ are the largest, compared to graduates with non-accounting degrees. Lim et al's (2008) study also reveals similar findings of accounting graduates having better employment outcomes. Perhaps it does not come off as surprising when we find no significant marginal effects of having degrees in entrepreneur, business, or economics on the probability of having a job that is commensurate with those qualifications. Compared to an accounting degree, these can be regarded as more general degrees. We do not find any significant marginal effects of having an entrepreneurship degree on the probabilities of any of the four outcomes. The results however reveal that graduates with a business degree are less likely to be become entrepreneurs. Having good CGPA contributes to higher chances of getting jobs that match with qualifications. CGPA does not seem to have any significant effects on the probabilities of the other three outcomes. Graduates with the lowest level of English proficiency are less likely to have a job that is commensurate with their degrees, compared to graduates with the highest level of English proficiency, i.e. those with MUET Band 4 to Band 6.

\section{CONCLUSION}

In this study, we have collected data on actual job choices that fresh graduates have made, their monthly earnings, and whether or not they are employed (at the time of our survey). With these data, our study contributes to the empirical literature and focuses on the issue of whether or not entrepreneurship education is significant in influencing earnings, employment probabilities, and types of job. The main conclusions from our findings are (i) graduate entrepreneurs' monthly earnings are higher than graduates employed in qualification-mismatched jobs, but lower than those with qualification-matching jobs, (ii) graduates with entrepreneurship degrees earn less than those with non-entrepreneurship degrees, (iii) having an entrepreneurship degree has no significant influence on employment chances, and (iv) an entrepreneurship degree also is also insignificantly associated with any of the probabilities of landing a job that is either commensurate or incommensurate with one's degree, or the probabilities of being unemployed.

One of the major limitations of this study is the relatively small number of respondents with entrepreneur-related degrees, only about 130 out of a total of 1,706 (i.e. less than 
$10 \%$ ). This small number may affect the power of our statistical tests, where the power of a test is the probability that the test correctly rejects a false null hypothesis. Another limitation of this study is perhaps our target population is from only two universities, due to constraints in resources. We suggest similar future research work to do a purposive sampling to ensure a reasonably large number of graduates with entrepreneur-related degrees, and those who are entrepreneurs.

\section{ACKNOWLEDGEMENT}

The authors are grateful for the research funding provided by the Malaysian government's Fundamental Research Grant Scheme (FRGS S/O Code 12617).

\section{REFERENCES}

Cheng, M. Y., Chan, W. S., \& Mahmood, A. (2009). The effectiveness of entrepreneurship education in Malaysia. Education + Training, 51(7), 555-566.

Global Entrepreneurship Monitor (GEM). (2010). GEM Malaysian 2010 Report. London: London Business School, Global Entrepreneurship Research Association.

Lim, H. E. (2007). Estimating the employment performance indicator: The case of Universiti Utara Malaysia Graduates. Singapore Economic Review, 52(1), 73-91.

Lim, H. E. (2010). Predicting low employability graduates: The case of Universiti Utara Malaysia. Singapore Economic Review, 55(3), 523-535.

Lim, H. E., \& Bakar, N. A. (2004). Unemployment duration of graduates of Universiti Utara Malaysia: the impact of English language proficiency. Malaysian Journal of Economic Studies, 41(1-2), 1-20.

Lim, H. E., Rich, J., \& Harris, M. N. (2008). Employment outcomes of graduates: The case of Universiti Utara, Malaysia. Asian Economic Journal, 22(3), 321-341.

Ministry of Higher Education (MOHE). (2011). Statistics of higher education of Malaysia. Malaysia, Putrajaya: Ministry of Higher Education.

Mohamad, N., Lim, H. E., Yusof, N., Kassim, M., Abdullah, H. (2014). Estimating the choice of entrepreneurship as a career: The case of Universiti Utara Malaysia. International Journal of Business and Society, 15(1), 65-80.

Mohamed, Z., Rezai, G., Shamsudin, M. N., \& Mahmud, M. M. (2012). Enhancing young graduates' intention towards entrepreneurship development in Malaysia. Education + Training, 54(7), 605-618.

Ooi, Y.K., Selvarajah, C., \& Meyer, D. (2011). Inclination towards entrepreneurship among university students: An empirical study of Malaysian university students. International Journal of Business and Social Science, 2(4), 206-220.

Othman, N., Hashim, N., \& Wahid, H. A. (2012). Readiness towards entrepreneurship education. Education + Training, 54(8/9), 697-708.

Sandhu, M. S., Sidique, S. F., \& Riaz, S. (2011). Entrepreneurship barriers and entrepreneurial inclination among Malaysian postgraduate students. International Journal of Entrepreneurial Behavior \& Research, 17(4), 428-449. 